\title{
Clinical outcomes of ceramic femoral prosthesis in total knee arthroplasty: a systematic review
}

\author{
Shuai Xiang ${ }^{\dagger}$, Yan Zhao ${ }^{\dagger}$, Zeng Li, Bin Feng and Xisheng Weng ${ }^{*}$
}

\begin{abstract}
Purpose: Ceramic bearings have been widely used in total hip arthroplasty (THA), which resulted in satisfactory clinical outcomes due to the excellent tribological characteristics of the implants. However, ceramic components are not commonly used in total knee arthroplasty (TKA) because of brittleness. This study aimed to gather and analyze information regarding the clinical outcomes (including survival without revision, causes of revision, functional outcome, and incidence of loosening) and reach a definitive conclusion about the use of ceramic femoral components in total knee arthroplasty.

Methods: MEDLINE, EMBASE, Cochrane, and ClinicalTrials.gov databases were searched for studies that reported the clinical and/or radiological outcomes with or without survival data of ceramic TKA implants and that included more than 10 patients with a minimum of 1 year follow-up.

Results: From an initial sample of 147, there were 14 studies that met the inclusion criteria. Overall, there was a notable enhancement of joint function after the procedure, with a satisfactory mid- and long-term survival of the ceramic components, which is comparable to that of the conventional alloy components reported previously. In addition, the revision rate was reported to be between $0 \%$ and $14.37 \%$ according to the included studies. However, revision due to aseptic loosening, wear, and component fracture appeared to be rare, demonstrating the safety of in vivo use of ceramic bearings in the TKA procedure.

Conclusions: Ceramic TKA implants show similar post-operative clinical results and survival rate compared to their conventional metallic counterparts. Our results confirmed the safety of in vivo use of ceramic bearings in TKA, with rare implant breakage and aseptic loosening. Considering the excellent characteristics of the tribology of ceramics, the clinical use of ceramic prostheses in TKA could be promising.
\end{abstract}

Keywords: Ceramics, Total knee arthroplasty, Outcomes

\section{Introduction}

Total knee arthroplasty (TKA) is regarded as an effective and reliable treatment to restore joint function for end-stage arthritis [1-3]. Today, cobalt-chrome-molybdenum alloy (CoCrMo) is widely used in TKA femoral components. According to several reports, over 90\% CoCrMo TKA prostheses successfully survived 15-year post-operative use [4-6]. Several factors including aseptic loosening, as well as metal hypersensitivity, which

\footnotetext{
* Correspondence: xishengweng@163.com

Shuai Xiang and Yan Zhao contributed equally to this article

Department of Orthopaedic Surgery, Peking Union Medical College Hospital, Peking Union Medical College, Chinese Academy of Medical Science, Beijing 100730, China
}

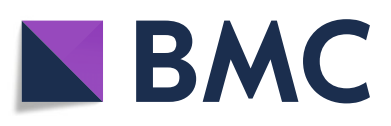

(c) The Author(s). 2019 Open Access This article is distributed under the terms of the Creative Commons Attribution 4.0 International License (http://creativecommons.org/licenses/by/4.0/), which permits unrestricted use, distribution, and reproduction in any medium, provided you give appropriate credit to the original author(s) and the source, provide a link to the Creative Commons license, and indicate if changes were made. The Creative Commons Public Domain Dedication waiver (http://creativecommons.org/publicdomain/zero/1.0/) applies to the data made available in this article, unless otherwise stated. affects over $10 \%$ of the population, could jeopardize TKA $[7,8]$. Debris generated by wear of polyethylene (PE) components could induce osteolysis, resulting in aseptic loosening of the TKA prosthesis [9]. To reduce polyethylene wear and prolong the life span of the implant, modification of the articulating surfaces was addressed and the design of the prosthesis was improved $[10,11]$. The application of ceramics instead of cobalt-chromium alloys for the femoral component could be a promising approach.

Ceramic materials, including zirconia, alumina, and their compounds, have excellent characteristics of tribology and 
biocompatibility and have been introduced as an alternative bearing in the design of articular prostheses for decades, especially in femoral head prostheses in total hip replacement. In several wear-simulation studies, a significantly reduced amount of polyethylene wear was observed in oxidized zirconium compared with conventional cobalt chromium alloy [12]. Recent clinical studies in total hip arthroplasty (THA) also demonstrated this advantage of decreasing polyethylene wear and thus alleviating aseptic osteolysis compared with patients in a metal-PE group [13]. Furthermore, the debris produced from the metal-PE bearing surface could elicit allergenic reactions in some of the patients receiving the TKA procedure. The medical-grade ceramic prosthesis is made of a bio-inert material and has been proved to be safe in vivo, providing a promising alternative for patients allergic to metallic materials [14].

However, contrary to their wide use in THA, ceramic bearings are rarely used in TKA, although the first ceramic TKA prosthesis was designed and used in the 1980s. However, its high brittleness and potential for implant fracture in vivo restrict its application in TKA [15, 16]. Besides, because of the smooth surface of the ceramic component, the adhesive strength of the bone cement has been questioned for some time $[17,18]$. In the last decade, several studies reported long-term outcomes and survival, as well as tribological statistics of ceramic knee implants, and a few of them compared the clinical and radiological outcomes between ceramic knee prostheses and metal prostheses, demonstrating similar long-term outcomes and survival between these two types of implants. These studies provided us with new and solid evidence for the clinical use of ceramics in TKA.

The purpose of this study was to systematically review the published literature regarding the use of ceramic knee implants in TKA to evaluate their clinical outcomes and long-term survival as well as to determine whether the ceramic knee prosthesis is suitable for TKA. This study should provide new evidence for surgeons, allowing them to better understand the safety and superiority of ceramic knee prostheses and to eliminate prejudice against their use for TKA.

\section{Materials and methods}

\section{Search strategy}

We searched MEDLINE, EMBASE, Cochrane, and ClinicalTrials.gov databases to retrieve relevant literature up to March 2017. The following terms were used for the search: total knee replacement, total knee arthroplasty, ceramic, aluminum oxide, and zirconia. The references of articles of interest were also screened for potential studies missed in the primary search. Additionally, we supplemented our search for articles in journals by hand and contacted the authors for unpublished data if necessary.
All searches were limited to human studies. Only articles in English were included. If more than one article reported data from the same cohort, only the latest one was included as the identifier. If possible, this article integrated the data from different reports of that cohort.

\section{Inclusion criteria and exclusion criteria}

1. Type of studies. Clinical trials, prospective, or retrospective (one arm or controlled) were eligible. Articles reporting in vitro studies and simulations were excluded.

2. Participants. Patients had a diagnosis of osteoarthritis or rheumatoid arthritis, and TKA was the preferred treatment. Patients who underwent TKA due to malignancy, trauma, or other causes were excluded.

3. Intervention. The majority of the studies included patients who underwent primary TKA, with the prosthesis made of ceramics. There was no restriction on the specific chemical components of the implant. If there was a control group, these patients received TKA with a metal implant.

4. Outcomes. We included articles reporting at least one of the following parameters: peri-operative measurements (including blood loss, post-operative drainage, pain, time of operation, and length of hospitalization), post-operative complications, rate and reasons for revision, survival curve (Kaplan-Meier curve) of the implant, ability to walk, range of motion of the knee joint after surgery, or other assessment of knee joint function. The observation of a radiolucent line on X-ray image was considered equivalent to loosening.

\section{Data extraction}

Data were extracted by two investigators independently using a collection form designed by our group. Data presented only in graphs and figures were extracted whenever possible, but were included only if consensus were achieved. Data not published was acquired by contact with the original investigators and if that failed, calculated with available data. For articles that did not report a Kaplan-Meier curve, we constructed the curve according to the data available when possible.

\section{Results}

\section{Search result}

A total of 147 records were retrieved, among which 134 were acquired through database searching, and 13 identified through other sources. There were 140 articles remaining after removing the duplicates, and 81 of them were screened based on the abstract, among which 23 full-text articles were further accessed for eligibility. 
After a thorough evaluation, 14 reports were included in this systematic review [19-32] (Fig. 1).

\section{Characteristics of the included studies}

The characteristics of the studies included are summarized in Table 1. A ceramic femoral prosthesis was implanted in all studies. Three studies compared ceramic prostheses with metal prostheses. The duration of follow-up ranged from 1 year to more than 18 years.

\section{Function of knee joints}

Data regarding the range of motion, the HSS score, and Knee Society knee-function (KSS) score were extracted from the included studies (Tables 2 and 3). For the evaluation of the motion of knee joints, two studies reported the range of motion, and seven studies reported the range of flexion and/or range of extension individually. For the assessment of knee joint function, the HSS scores were used in four studies, and the KSS scores were calculated in six studies. According to the original reports of the studies, the HSS and the KSS scores improved significantly after TKA with ceramic femoral implants.

\section{Revision and loosening}

The rate and detailed causes of revision and loosening are summarized in Table 4. Major causes of revision included breakage of the prosthesis, infection, aseptic loosening, instability, and wear of the prosthesis. Generally, the rate of revision increased as the duration of follow-up increased. Wear of the prosthesis, a common concern for ceramic prostheses, only occurred in three knees after following up for 18.1 years. Breakage of the prosthesis, another major concern for ceramic implants, occurred in 3 patients after a minimum follow-up of 5 years. The data were pooled to generate an overall estimate of the rate of revision, which was 0.03 (95\% confidential interval 0.01 to $0.04, I^{2}=64.3 \%$, $P=0.002$ ) (Fig. 2).

The adhesion between the prosthesis and adjacent tissue was evaluated by X-ray, and radiolucent lines were considered indicators for prosthetic loosening. The appearance of radiolucent lines around the femoral component, tibial component, and the patella is summarized individually in Table 4.

\section{Survival curve of ceramic prostheses}

The survival of ceramic prostheses is illustrated by a Kaplan-Meier curve as shown in Fig. 3. Four studies

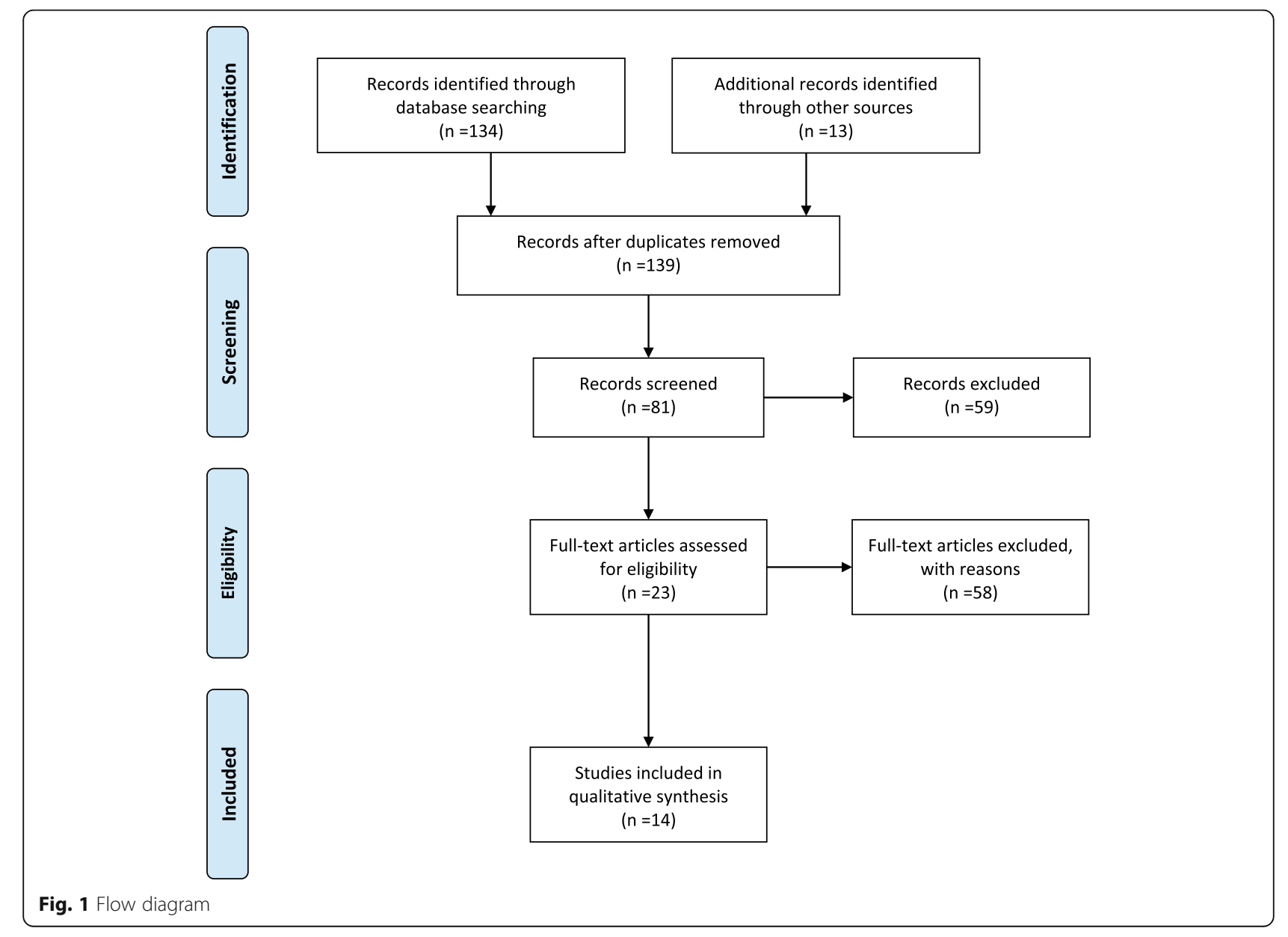


Table 1 Characteristics of studies included

\begin{tabular}{|c|c|c|c|c|c|c|}
\hline Author, year & Patients & Knees & Age at operation & Type of femur prosthesis & Type of tibial prosthesis & Duration of follow-up (years) \\
\hline Akagi, 2000 [19] & 136 & 182 & $68(39-84)$ & Alumina & Metal & $5.8(3.9-9.0)$ \\
\hline Koshino, 2002 [20] & 64 & 90 & $59(38-81)$ & Alumina & Alumina & $4.67(2.25-8.1)$ \\
\hline Laskin, 2003 [21] & 73 & 73 & $\mathrm{~N} / \mathrm{A}$ & Zirconia & Metal & 2 \\
\hline Bal, 2006 [22] & 33 & 36 & $59(29-80)$ & Zirconia & Metal & $2.6(2-3.3)$ \\
\hline Majima, 2008 [23] & 110 & 110 & $66(55-77)$ & Alumina & Metal & $5.5(3-10.3)$ \\
\hline lida, 2012 [24] & 80 & 107 & $72(45-86)$ & Alumina & Metal & $5(1-7)$ \\
\hline Innocenti, 2014 [25] & 83 & 87 & N/A & Zirconia & Metal & $11.3(10-12.6)$ \\
\hline Park, 2014 [26] & 67 & 84 & $55(32-75)$ & Zirconia/niobium & Metal & $5.16(4.25-7.33)$ \\
\hline Ahmed, 2015 & 278 & 303 & $68(45-89)$ & Zirconia & Metal & $9.7(8.3-11.6)$ \\
\hline Bergschmidt, 2015 [27] & 107 & 109 & $67.8(52-75)$ & Alumina/zirconia & Metal & $4.08(0-5)$ \\
\hline Bergschmidt, 2016 [28] & 21 & 21 & $66.9(38-79)$ & Alumina/zirconia & Metal & 5 \\
\hline Meier, 2016 [29] & 28 & 32 & $66.87(46-83)$ & Alumina/zirconia & Alumina/zirconia & 1 \\
\hline Nakamura, 2017 [30] & 51 & 37 & $72(45-86)$ & Alumina & Metal & $11.8(10-13)$ \\
\hline Nakamura, 2017 [30] & 114 & 167 & $68.5(39-91)$ & Alumina/yttria & Metal or alumina & $18.1(15-24.7)$ \\
\hline Grand total & 1245 & 1438 & & & & \\
\hline
\end{tabular}

Duration of follow-up was presented as a mean value with range in the brackets. N/A indicated the corresponding data were unavailable

reported excellent survival of ceramic prostheses at follow-up, which was reflected by a survival rate of $98 \%$ 5 years after the operation and 95\% 20 years after the operation. However, Bergschmidt reported a lower survival rate after the arthroplasty, with a much shorter survival period. The possible explanation was that several patients underwent unexpected events shortly after discharge (involving trauma), and needed revision for infection of the prosthesis. Additionally, we plotted a scatter diagram of the survival rate and duration based on the information from the studies included and estimated the survival-time relationship by linear approximation (Fig. 4). The function is as follows:
Rate of survival $=-0.0002 \times$ time (months) after operation $+1.0027$

\section{Discussion}

Key findings

Given the uncertainty regarding the clinical performance of ceramic TKA components, we aimed to explore whether differences exist between the conventionally used alloy components and ceramic components. By summarizing the previous reports on ceramic TKA prostheses, in this study, we sought to systematically evaluate

Table 2 Function of knee joints before and after total knee arthroplasty with ceramic femoral implants

\begin{tabular}{|c|c|c|c|c|c|c|}
\hline \multirow[t]{2}{*}{ Author, year } & \multicolumn{2}{|l|}{ HSS } & \multicolumn{2}{|c|}{ Knee Society knee score } & \multicolumn{2}{|c|}{ Knee Society function score } \\
\hline & Pre-op & Post-op & Pre-op & Post-op & Pre-op & Post-op \\
\hline Akagi, 2000 [19] & 44.5 & 86.3 & $\mathrm{~N} / \mathrm{A}$ & $\mathrm{N} / \mathrm{A}$ & N/A & N/A \\
\hline Koshino, 2002 [20] & N/A & N/A & $41 \pm 16$ & $83 \pm 14$ & $29 \pm 22$ & $50 \pm 29$ \\
\hline Bal, 2006 [22] & N/A & N/A & 39.9 & 92.3 & 42.3 & 69 \\
\hline lida, 2012 [24] & N/A & N/A & $14 \pm 13$ & $90 \pm 10$ & $47 \pm 13$ & $76 \pm 22$ \\
\hline Innocenti, 2014 [25] & N/A & N/A & 36 & 84 & 37 & 83 \\
\hline Park, 2014 [26] & N/A & N/A & $39(0-70)$ & $92(31-100)$ & $53(0-90)$ & $90(35-100)$ \\
\hline Bergschmidt, 2015 [27] & $55.1 \pm 11.5$ & $85.6 \pm 9.6$ & N/A & N/A & N/A & N/A \\
\hline Bergschmidt, 2016 [28] & $58.7 \pm 12.7$ & $88.5 \pm 12.3$ & $\mathrm{~N} / \mathrm{A}$ & N/A & N/A & N/A \\
\hline Meier, 2016 [29] & $\mathrm{N} / \mathrm{A}$ & N/A & $38.84 \pm 15.75$ & $93.66 \pm 7.41$ & $53.61 \pm 18.45$ & $95.47 \pm 12.01$ \\
\hline Nakamura, 2017 [30] & $\mathrm{N} / \mathrm{A}$ & N/A & $14 \pm 13$ & $89 \pm 11$ & $47 \pm 13$ & $68 \pm 21$ \\
\hline Nakamura, 2017 [30] & N/A & N/A & $39.1 \pm 17.9$ & $92.8 \pm 7.2$ & $36.0 \pm 19.1$ & $47.0 \pm 22.9$ \\
\hline
\end{tabular}


Table 3 Range of motion of knee joints before and after total knee arthroplasty with ceramic femoral implants

\begin{tabular}{|c|c|c|c|c|c|c|}
\hline \multirow[t]{2}{*}{ Author, year } & \multicolumn{2}{|c|}{ Flexion (degrees) } & \multicolumn{2}{|c|}{ Extension (degrees) } & \multicolumn{2}{|c|}{ Range of motion (degrees) } \\
\hline & Pre-op & Post-op & Pre-op & Post-op & Pre-op & Post-op \\
\hline Akagi, 2000 [19] & 119 & 124 & -10.8 & -0.3 & N/A & N/A \\
\hline Koshino, 2002 [20] & N/A & N/A & N/A & N/A & N/A & N/A \\
\hline Laskin, 2003 [21] & N/A & 117 & N/A & N/A & N/A & N/A \\
\hline Bal, 2006 [22] & 100 & 119 & -7 & 0 & N/A & N/A \\
\hline Majima, 2008 [23] & N/A & $112 \pm 17$ & N/A & N/A & N/A & N/A \\
\hline lida, 2012 [24] & $110 \pm 20$ & $115 \pm 19$ & $-8 \pm 8$ & $-1 \pm 3$ & $104 \pm 23$ & $114 \pm 20$ \\
\hline Innocenti, 2014 [25] & 92 & 118 & N/A & N/A & N/A & N/A \\
\hline Park, 2014 [26] & N/A & N/A & N/A & N/A & N/A & N/A \\
\hline Ahmed, 2015 & $116(70-140)$ & $114(70-130)$ & N/A & N/A & N/A & N/A \\
\hline Bergschmidt, 2015 [27] & N/A & N/A & N/A & N/A & $108.6 \pm 15.4$ & $111.4 \pm 15.1$ \\
\hline Bergschmidt, 2016 [28] & N/A & N/A & N/A & N/A & $111.3 \pm 18.0$ & $121.1 \pm 29.6$ \\
\hline Meier, 2016 [29] & N/A & N/A & N/A & N/A & N/A & N/A \\
\hline Nakamura, 2017 [30] & $110 \pm 20$ & $117 \pm 22$ & $-8 \pm 8$ & $-1 \pm 4$ & N/A & N/A \\
\hline Nakamura, 2017 [30] & $118.1 \pm 19.8$ & $123.7 \pm 19.0$ & $-10.7 \pm 10.7$ & $-1.6 \pm 4.9$ & N/A & N/A \\
\hline
\end{tabular}

All data were presented as mean \pm standard deviation, with range in bracket. $N / A$ indicated the corresponding data were unavailable

Table 4 Revision and radiolucent lines after total knee arthroplasty with ceramic femoral prosthesis

\begin{tabular}{|c|c|c|c|c|c|c|c|c|c|c|c|c|c|}
\hline \multirow[t]{2}{*}{ Author, year } & \multirow[b]{2}{*}{$\begin{array}{l}\text { No. of } \\
\text { knees }\end{array}$} & \multirow{2}{*}{$\begin{array}{l}\text { Duration of } \\
\text { follow-up (years) }\end{array}$} & \multicolumn{8}{|l|}{ Revision } & \multicolumn{3}{|c|}{ Radiolucent line } \\
\hline & & & $\begin{array}{l}\text { Breakage of } \\
\text { prosthesis }\end{array}$ & Infection & $\begin{array}{l}\text { Aseptic } \\
\text { loosening }\end{array}$ & Instability & Wear & Others & Total & $\begin{array}{l}\text { Rate of revision } \\
\text { in total }\end{array}$ & Femoral & Tibial & Patellar \\
\hline $\begin{array}{l}\text { Akagi, } 2000 \\
{[19]}\end{array}$ & 182 & 5.8 & 1 & 5 & 0 & 2 & 0 & 0 & 8 & $4.40 \%$ & 0 & 0 & 0 \\
\hline $\begin{array}{l}\text { Koshino, } \\
2002[20]\end{array}$ & 90 & 4.67 & 0 & 1 & 0 & 0 & 0 & 1 & 2 & $2.22 \%$ & 0 & 0 & 3 \\
\hline $\begin{array}{l}\text { Laskin, } 2003 \\
{[21]}\end{array}$ & 73 & 2 & 0 & 0 & 0 & 0 & 0 & 1 & 1 & $1.37 \%$ & 0 & 2 & 0 \\
\hline Bal, 2006 [22] & 36 & 2.6 & 0 & 0 & 0 & 0 & 0 & 0 & 0 & $0.00 \%$ & 0 & 0 & 0 \\
\hline $\begin{array}{l}\text { Majima, } 2008 \\
{[23]}\end{array}$ & 110 & 5.5 & 1 & 0 & 0 & 0 & 0 & 1 & 2 & $1.82 \%$ & 0 & 3 & 0 \\
\hline $\begin{array}{l}\text { lida, } 2012 \\
{[24]}\end{array}$ & 107 & $5(1-7)$ & 0 & 0 & 0 & 0 & 0 & 1 & 1 & $0.93 \%$ & 0 & 0 & 0 \\
\hline $\begin{array}{l}\text { Innocenti, } \\
2014 \text { [25] }\end{array}$ & 87 & 11.3 & 0 & 0 & 2 & 0 & 0 & 0 & 2 & $2.30 \%$ & 2 & 12 & 0 \\
\hline $\begin{array}{l}\text { Park, } 2014 \\
{[26]}\end{array}$ & 84 & $5.16(4.25-7.33)$ & 0 & 0 & 0 & 0 & 0 & 0 & 0 & 0 & 1 & 17 & 0 \\
\hline Ahmed, 2015 & 303 & $9.7(8.3-11.6)$ & 8 in total & & & & & & & $2.64 \%$ & 18 in tota & & \\
\hline $\begin{array}{l}\text { Bergschmidt, } \\
2015 \text { [27] }\end{array}$ & 109 & 4.08 & 0 & 0 & 0 & 0 & 0 & 1 & 1 & $0.92 \%$ & 4 & 9 & 0 \\
\hline $\begin{array}{l}\text { Bergschmidt, } \\
2016 \text { [28] }\end{array}$ & 21 & 5 & 0 & 1 & 0 & 1 & 0 & 0 & 2 & $9.52 \%$ & 2 & 4 & 0 \\
\hline $\begin{array}{l}\text { Meier, } 2016 \\
\text { [29] }\end{array}$ & 32 & 1 & 0 & 0 & 0 & 0 & 0 & 0 & 0 & $0.00 \%$ & 1 & 5 & 0 \\
\hline $\begin{array}{l}\text { Nakamura, } \\
2017 \text { [30] }\end{array}$ & 37 & 11.8 & 0 & 0 & 0 & 0 & 0 & 1 & 1 & $2.70 \%$ & 13 & 17 & 0 \\
\hline $\begin{array}{l}\text { Nakamura, } \\
2017 \text { [30] }\end{array}$ & 167 & 18.1 & 1 & 9 & 3 & 4 & 3 & 4 & 24 & $14.37 \%$ & 44 & 3 & 0 \\
\hline Grand total & 1438 & & 3 & 16 & 5 & 7 & 3 & 10 & 52 & $3.62 \%$ & 67 & 72 & 3 \\
\hline
\end{tabular}




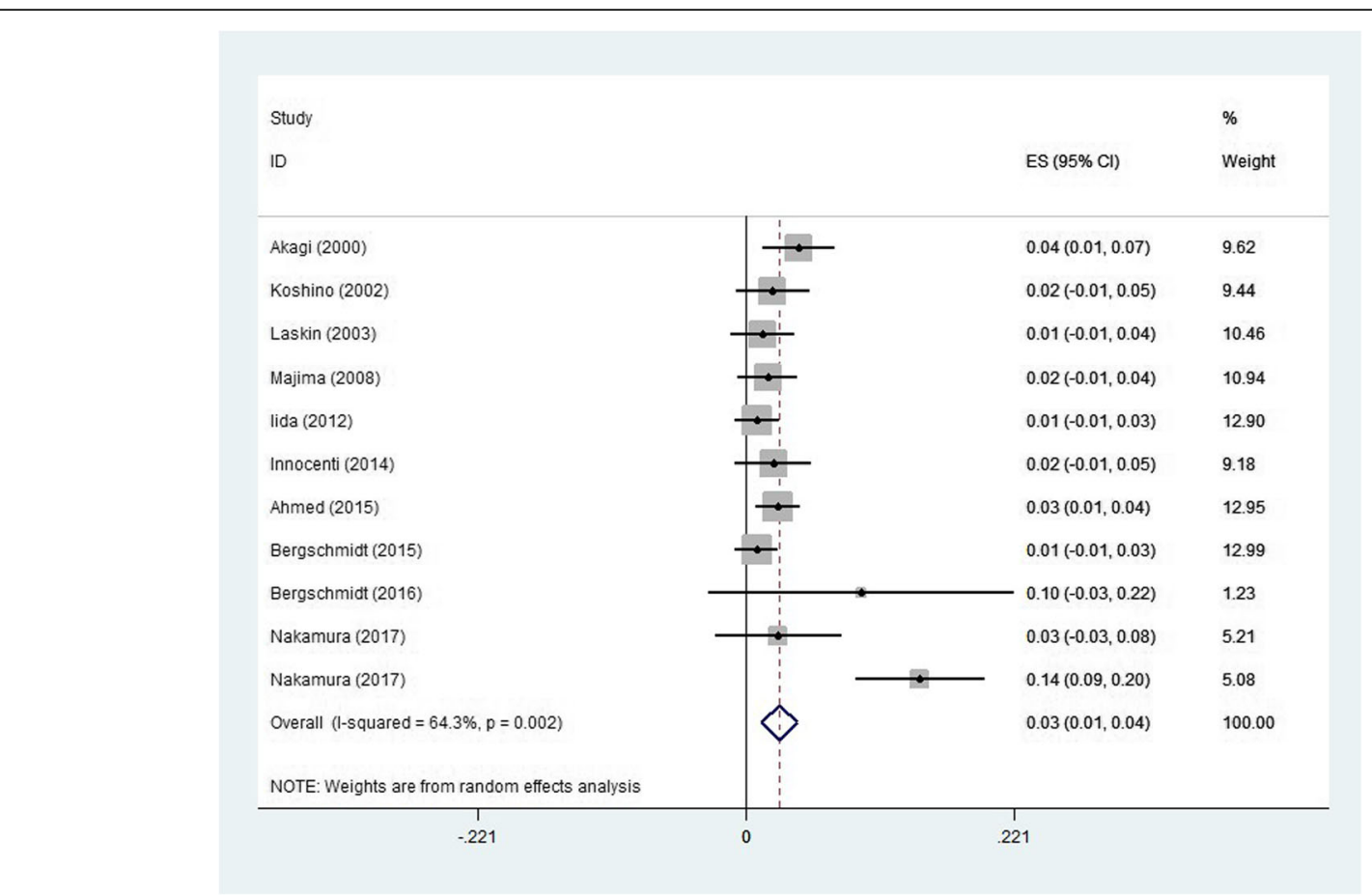

Fig. 2 Rate of revision

the clinical results, radiological results, and the survival of the ceramic prostheses. Our results demonstrated a marked enhancement of joint function after the procedure, with a satisfactory mid- and long-term survival of the ceramic components, which is comparable to that of the conventional alloy components reported previously. Furthermore, only a small fraction of revision procedures were performed due to polyethylene wear and aseptic loosening of the prosthesis, although radiolucent lines were observed in several studies. To the best of our knowledge, this is the first systematic evaluation of the results and safety of ceramic TKA components.

\section{Advantages and concerns of ceramic components}

Today, cobalt-chromium alloy is the most widely used prosthetic material in the femoral components of total knee prostheses, showing good recovery of joint function post-operatively. Long-term follow-up has demonstrated excellent survival of the conventional cobalt-chromium prosthesis $[2,4,5]$. However, according to these reports, the debris produced by wear of the polyethylene tibial insert has agglomerated in vivo and thus induced aseptic loosening of the components, and this appears to be one of the major reasons leading to failure of total knee arthroplasty [33]. Researchers have shown that accumulation of wear particles activates macrophages and

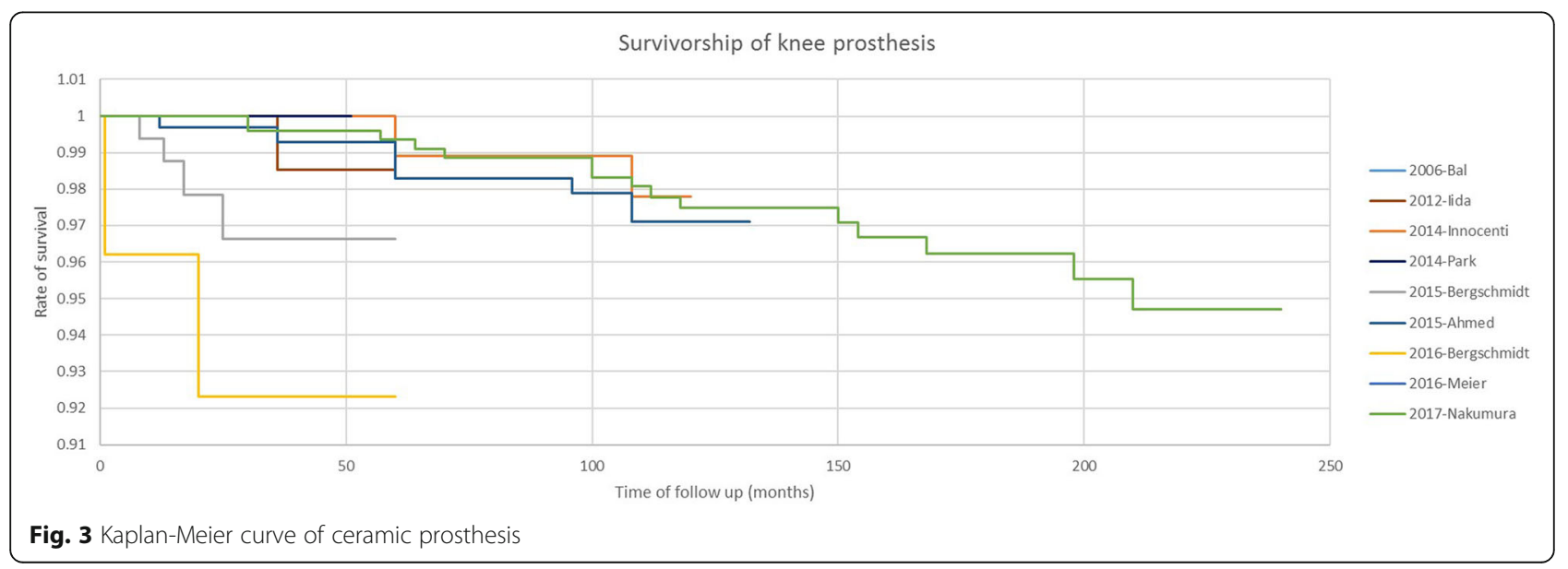




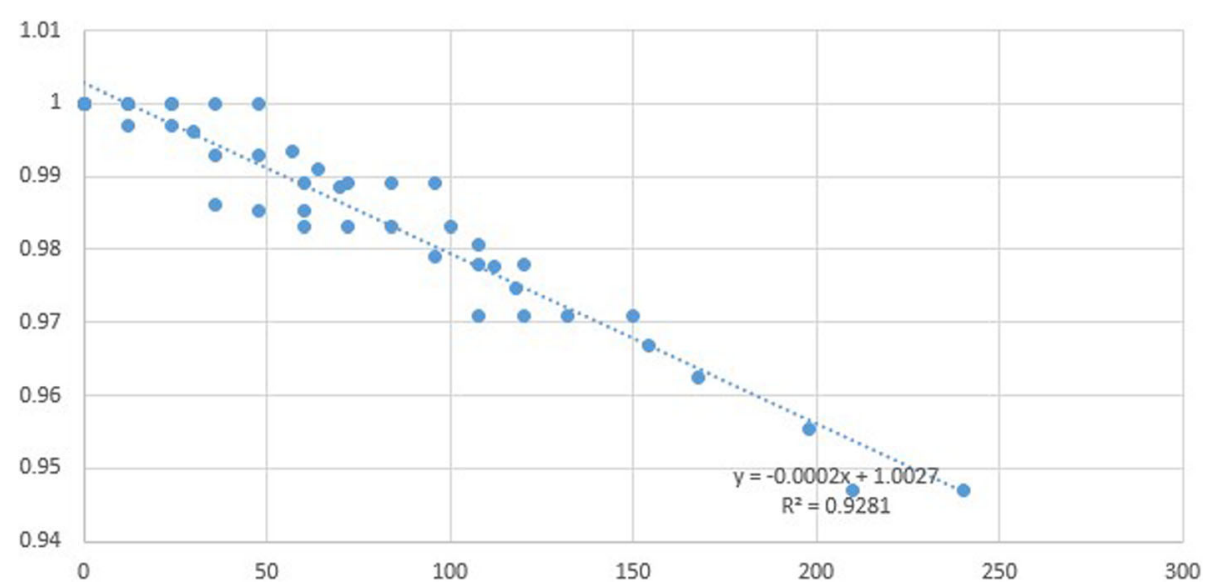

Fig. 4 Scatter diaphragm of survival rate and time

induces the release of inflammatory cytokines, which can be detected in the synovial fluid of failed TKAs [34]. These inflammatory cytokines are considered to play the pivotal part in periprosthetic bone resorption and implant loosening. Accordingly, a fundamental improvement would be to reduce the wear of the polyethylene insert and thereby decrease the occurrence of periprosthetic osteolysis and loosening of the components. In addition to improving the wear resistance of polyethylene by increasing the crosslinking, an alternative material with a more conforming surface and increased resistance to friction is needed for the articulating surface in TKA components.

With a proven superior surface conformity, high bending strength, and increased wear resistance, ceramic bearings (which are made of alumina and zirconia), have been used in THA components for many years [35]. Several in vivo and in vitro studies have also documented the superiority of ceramics in wear resistance when articulating against polyethylene compared with metal components [36, 37]. In recent years, several studies concerning the tribological statistics of ceramic knee implants have been performed and satisfactory results have been reported. Knee simulator studies held in various laboratories have also demonstrated the wear advantages of ceramic components over their alloy counterparts. The results from work by Ezzet and Spector showed that compared to cobalt-chromium, the wear rate of polyethylene against oxidized zirconium was reduced by nearly $50 \%$ after 5 million cycles of testing [38]. Another study conducted by White et al. found that after 2 million cycles of testing, the condition of polyethylene inserts articulating against oxidized zirconium was far better than against cobalt-chromium. There was also an improved surface texture for the oxidized zirconium [39]. Considering that in vitro simulator tests could not fully represent the clinical performance of the TKA components, retrieval studies were also carried out to evaluate the in vivo performance of the ceramic components. The results from Oonishi et al. showed a large difference in the wear rate for the polyethylene inserts articulating against cobalt-chromium femoral components, and the estimated linear-wear rate was 0.021 to $0.074 \mathrm{~mm} /$ year, while the wear rate in the group with alumina ceramic femoral components was low and stable, and was estimated as $0.026 \mathrm{~mm} /$ year. Furthermore, anterior-posterior-oriented scratches were found on the surface of both cobalt-chromium femoral components and polyethylene inserts using SEM, resulting from the flexion-extension movement of the joint. However, no scratching was found on the surface of the polyethylene inserts in the group with ceramic components, and the surface texture of the alumina femoral components remained unchanged [40].

In addition to having excellent wear resistance, the ceramic material is biologically inert, which is another advantage compared with the use of cobalt-chromium prostheses. Approximately, $15 \%$ of the population have been reported as being hypersensitive to nickel, usually in association with a cross-reactivity to cobalt [8]. In general, at least $1 \%$ nickel was included in the conventional cobalt-chromium femoral components, whereas there was no detectable level of nickel involved in the alumina and zirconia counterpart [41]. Moreover, the lower level of biological response to ceramic particles in vivo, represented by lower levels of tumor necrosis factor-alpha (TNF- $\alpha$ ) and prostaglandin E2 (PGE2), makes ceramic components a promising solution for those patients with allergy to metal ions.

Two major concerns of in vivo failure of the ceramic components are fracture of the implant due to its brittleness and decreased adhesive strength of the bone cement due to the conformed surface of the ceramic components [42]. In a 2-year follow-up study for ceramic-on-ceramic 
THA, Hamilton et al. reported 2 intraoperative ceramic liner fractures and 2 post-operative ceramic liners chipping, from a total of 177 THAs, and the overall rate of ceramic liner-related events was 2.2\% [42]. In addition, in a mechanical study concerning the strength of adhesion of the cement, the maximum adhesive strength to ceramic femoral components was substantially lower than to the $\mathrm{Co}-\mathrm{Cr}$ alloy counterpart under moist conditions $(P=0.0017)$ [18]. Furthermore, in an 18.5-year follow-up study concerning cemented alumina THA, Hamadouche et al. reported the debonding rate of the acetabular cup from the bone cement was $22 \%$ (19 out of 85 hips), leading to a sudden pain and a requirement for revision of the THA [37]. This high debonding rate exacerbated concern for the adhesive strength of ceramic components.

\section{Clinical outcomes of ceramic TKA components}

The procedure of TKA has been proven for the treatment of end-stage degenerative joint diseases. Among the included studies, a variety of evaluation parameters including range of motion, the HSS scores, and the KSS scores were used to assess the pre-operative and post-operative joint function. Overall, the post-operative joint function results were reported to be significantly improved, with an increased range of motion, greater range of flexion, enhanced HSS scores, and KSS scores in both short- and long-term follow-ups [19-23, 25, 2732]. In 3 studies with a 10-year or more follow-up, the KSS score was improved to 83-92, with a function score of $47-84$ at the last visit. The range of flexion at the last visit was also significantly improved, with a range of $118-123.7^{\circ}[25,30,31]$. In the past, there has been a lack of evidence for the long-term durability and clinical safety of ceramic TKA which limited the clinical use of the ceramic components. Recently, Nakamura reported a minimum follow-up of 15 years on ceramic tri-condylar knee implants (revision for any surgery or radiographic failure was the end point), Kaplan-Meier survival at 15 years was $94.0 \%$ (95\%CI 91.4-96.5\%). Other research on short- and mid-term survival of ceramic components also demonstrated satisfactory results, with a 5-year survival of $92-100 \%$ and a 10 -year survival of $97-98 \%$. In this study, we further systematically estimated the survival-time relationship by linear approximation, which is shown in Fig. 2. Among all these included studies, the revision rate was $0-14.37 \%$. However, revision due to aseptic loosening, wear, and component fracture appears to be rare. The two most common reasons for a revision procedure are infection and fracture caused by post-operative trauma. These results demonstrated the clinical safety of ceramic TKA prostheses.
In 2014, Innocenti et al. summarized the long-term follow-up of $\mathrm{Cr}-\mathrm{Co}$ femoral components using clinical scores and 10-year survival [25]. Although the post-operative range of motion was not reported, the results showed that the KSS score at 10 years was 83-96, while the function score was 74-83, with a 10-year survival over $91 \%$. Compared to the post-operative KSS score of Cr-Co components, the KSS of the ceramic components was comparable, while the function score was lower. Because the lower function scores of the ceramic components were reported in the Japanese population (47 and 68 , respectively), this discrepancy could be attributed to different recovery plans and daily activities in different populations, as well as possible bias during follow-up. Furthermore, we demonstrated ceramic TKA implants to be reliable, with a comparable 10-year survival with their alloy counterparts.

\section{Randomized clinical trials on ceramic TKA bearings}

In the past few decades, the use of oxidized zirconium femoral components has increased worldwide. In our literature search, we also took note of three prospective, randomized controlled studies focusing on the clinical outcomes and mid-term survival between procedures using oxidized zirconium femoral components and conventional $\mathrm{Co}-\mathrm{Cr}$ implants $[21,43,44]$. In a 2 -year follow-up, Laskin et al. reported no significant differences in KSS score and passive flexion range between the ceramic component group and the $\mathrm{Co}-\mathrm{Cr}$ group, while patients in the ceramic group showed a statistically significant increase in the rapidity of regaining flexion [21]. Similarly, two mid-term follow-ups of these randomized clinical trials showed no significant differences in clinical, subjective, radiological, and survival measurements between these two groups [43, 44]. Noticeably, in research conducted by Kim et al., the characteristics of the aspirated wear particles, including size, weight, and surface roughness were compared between the two groups, and no marked differences were found up to 7.5 years post-operatively [44]. However, these studies were not eligible for this review due to the lack of data of interest; hence, we excluded them in our review.

\section{Limitations}

By systematically reviewing these single-armed studies, we found that ceramic components could be used in the TKA procedure, with excellent long-term joint function and survival. However, because of the limited use of ceramic TKA components worldwide, RCTs and cohort studies comparing the long-term clinical results and survival between ceramic TKA components and conventional cobalt-chromium prostheses were not available. This may jeopardize the strength of this conclusion. More research on ceramic TKA components, especially 
comparative studies with a higher level of evidence, are needed to support the use of ceramic components in the TKA procedure.

\section{Conclusion}

Despite the limited use of ceramic knee implants worldwide, the KSS and survival rate of the ceramic femoral components in our study were comparable with those of the conventional metallic femoral components, while implant fractures rarely occurred. Considering the advanced tribological features of the ceramic components, we believe that these components could have a promising role in knee implant surgery.

\section{Abbreviations}

CoCrMo: Cobalt-chrome-molybdenum; THA: Total hip arthroplasty; TKA: Total knee arthroplasty

\section{Acknowledgements}

None

\section{Funding}

Not applicable.

\section{Availability of data and materials}

Not applicable

\section{Authors' contributions}

SX and YZ designed the study, analyzed the data, and wrote the manuscript. ZL helped write and modify the manuscript. BF participated in the data interpretation. XSW conceived the idea of this study and participated in manuscript modification. All authors read and approved the final manuscript.

\section{Authors' information}

All the authors are members of department of Orthopaedic Surgery, Peking Union Medical College Hospital, Peking Union Medical College, Chinese Academy of Medical Science, Beijing

\section{Ethics approval and consent to participate}

Not applicable

\section{Consent for publication}

Not applicable

\section{Competing interests}

The authors declare that they have no competing interests.

\section{Publisher's Note}

Springer Nature remains neutral with regard to jurisdictional claims in published maps and institutional affiliations.

Received: 3 July 2018 Accepted: 5 February 2019

Published online: 19 February 2019

\section{References}

1. Buechel FF Sr. Long-term followup after mobile-bearing total knee replacement. Clin Orthop Relat Res. 2002:404:40-50.

2. Bordini B, Ancarani C, Fitch DA. Long-term survivorship of a medial-pivot total knee system compared with other cemented designs in an arthroplasty registry. J Orthop Surg Res. 2016;11:44.

3. Ji HM, Ha YC, Baek JH, Ko YB. Advantage of minimal anterior knee pain and long-term survivorship of cemented single radius posterior-stabilized total knee arthroplasty without patella resurfacing. Clin Orthop Surg. 2015;7(1): 54-61.

4. Callaghan JJ, Martin CT, Gao Y, Pugely AJ, Liu SS, Goetz DD, Kelley SS, Johnston RC. What can be learned from minimum 20-year followup studies of knee arthroplasty? Clin Orthop Relat Res. 2015;473(1):94-100.
5. Karachalios T, Varitimidis S, Bargiotas K, Hantes M, Roidis N, Malizos KN. An 11- to 15-year clinical outcome study of the advance medial pivot total knee arthroplasty: pivot knee arthroplasty. Bone Joint J. 2016;98-B(8):1050-5.

6. Victor J, Ghijselings S, Tajdar F, Van Damme G, Deprez P, Arnout N, Van Der Straeten C. Total knee arthroplasty at 15-17 years: does implant design affect outcome? Int Orthop. 2014;38(2):235-41.

7. Harrysson OL, Robertsson O, Nayfeh JF. Higher cumulative revision rate of knee arthroplasties in younger patients with osteoarthritis. Clin Orthop Relat Res. 2004;421:162-8.

8. Frigerio E, Pigatto PD, Guzzi G, Altomare G. Metal sensitivity in patients with orthopaedic implants: a prospective study. Contact Dermatitis. 2011;64(5): 273-9.

9. Kovacik MW, Gradisar IA Jr, Haprian JJ, Alexander TS. Osteolytic indicators found in total knee arthroplasty synovial fluid aspirates. Clin Orthop Relat Res. 2000;379:186-94.

10. Sathasivam S, Walker PS. The conflicting requirements of laxity and conformity in total knee replacement. J Biomech. 1999;32(3):239-47.

11. Gomoll A, Wanich T, Bellare A. J-integral fracture toughness and tearing modulus measurement of radiation cross-linked UHMWPE. J Orthop Res. 2002;20(6):1152-6

12. Minoda $Y$, Kobayashi A, Iwaki H, Iwakiri K, Inori F, Sugama R, Ikebuchi M, Kadoya Y, Takaoka K. In vivo analysis of polyethylene wear particles after total knee arthroplasty: the influence of improved materials and designs. $J$ Bone Joint Surg American Vol. 2009;91(Suppl 6):67-73.

13. Oonishi H, Clarke IC, Good V, Amino H, Ueno M. Alumina hip joints characterized by run-in wear and steady-state wear to 14 million cycles in hip-simulator model. J Biomed Mater Res A. 2004;70(4):523-32.

14. Faschingbauer $M$, Renner $L$, Boettner F. Allergy in total knee replacement. does it exist?: review article. HSS J. 2017;13(1):12-9.

15. Traina F, De Fine M, Di Martino A, Faldini C. Fracture of ceramic bearing surfaces following total hip replacement: a systematic review. Biomed Res Int. 2013;2013:157247.

16. Traina F, Tassinari E, De Fine M, Bordini B, Toni A. Revision of ceramic hip replacements for fracture of a ceramic component: AAOS exhibit selection. J Bone Joint Surg American. 2011;93(24):e147.

17. Bergschmidt P, Dammer R, Zietz C, Finze S, Mittelmeier W, Bader R. Adhesive strength of total knee endoprostheses to bone cement-analysis of metallic and ceramic femoral components under worst-case conditions. Biomed Tech (Berl). 2016;61(3):281-9.

18. Kumahashi N, Uchio Y, Kitamura N, Satake S, Iwamoto M, Yasuda K. Biomechanical comparison of the strength of adhesion of polymethylmethacrylate cement to zirconia ceramic and cobalt-chromium alloy components in a total knee arthroplasty. J Orthop Sci. 2014;19(6):940-7.

19. Akagi M, Nakamura T, Matsusue Y, Ueo T, Nishijyo K, Ohnishi E. The Bisurface total knee replacement: a unique design for flexion. Four-to-nine-year followup study. J Bone Joint Surg American Vol. 2000;82-a(11):1626-33.

20. Koshino T, Okamoto R, Takagi T, Yamamoto K, Saito T. Cemented ceramic YMCK total knee arthroplasty in patients with severe rheumatoid arthritis. J Arthroplasty. 2002:17(8):1009-15.

21. Laskin RS. An oxidized Zr ceramic surfaced femoral component for total knee arthroplasty. Clin Orthop Relat Res. 2003;416:191-6.

22. Bal BS, Greenberg DD, Buhrmester L, Aleto TJ. Primary TKA with a zirconia ceramic femoral component. J Knee Surg. 2006;19(2):89-93.

23. Majima T, Yasuda K, Tago H, Aoki Y, Minami A. Clinical results of posterior cruciate ligament retaining TKA with alumina ceramic condylar prosthesis: comparison to $\mathrm{Co}-\mathrm{Cr}$ alloy prosthesis. Knee Surg Sports Traumatol Arthrosc. 2008;16(2):152-6.

24. lida T, Minoda Y, Kadoya Y, Matsui Y, Kobayashi A, Iwaki H, Ikebuchi M, Yoshida T, Nakamura H. Mid-term clinical results of alumina medial pivot total knee arthroplasty. Knee Surg Sports Traumatol Arthrosc. 2012;20(8): 1514-9.

25. Innocenti M, Matassi F, Carulli C, Nistri L, Civinini R. Oxidized zirconium femoral component for TKA: a follow-up note of a previous report at a minimum of 10 years. Knee. 2014;21(4):858-61.

26. Park DH, Leong J, Palmer SJ. Total Knee Arthroplasty with an Oxidised Zirconium Femoral Component: A 5-Year Follow-up Study. J Orthop Surg. 2014;22(1):75-9.

27. Bergschmidt $P$, Bader $\mathrm{R}$, Ganzer $\mathrm{D}$, Hauzeur C, Lohmann CH, Kruger $\mathrm{A}$, Ruther W, Tigani D, Rani N, Esteve JL, et al. Prospective multi-centre study on a composite ceramic femoral component in total knee arthroplasty: Five-year clinical and radiological outcomes. Knee. 2015;22(3):186-91. 
28. Bergschmidt P, Ellenrieder M, Bader R, Kluess D, Finze S, Schwemmer B, Mittelmeier W. Prospective comparative clinical study of ceramic and metallic femoral components for total knee arthroplasty over a five-year follow-up period. Knee. 2016;23(5):871-6.

29. Meier E, Gelse K, Trieb K, Pachowsky M, Hennig FF, Mauerer A. First clinical study of a novel complete metal-free ceramic total knee replacement system. J Orthop Surg Res. 2016;11:21.

30. Nakamura S, Ito H, Nakamura K, Kuriyama S, Furu M, Matsuda S. Long-term durability of ceramic tri-condylar knee implants: a minimum 15-year followup. J Arthroplasty. 2017; 32(6):1874-79.

31. Nakamura S, Minoda Y, Nakagawa S, Kadoya Y, Takemura S, Kobayashi A, Mizokawa S, Ohta Y, Takahashi S, Yamamura K, et al. Clinical results of alumina medial pivot total knee arthroplasty at a minimum follow-up of 10 years. Knee. 2017;24(2):434-8.

32. Ahmed I, Salmon $\amalg$, Waller A, Watanabe H, Roe JP, Pinczewski LA. Total knee arthroplasty with an oxidised zirconium femoral component: ten-year survivorship analysis. Bone Joint J. 2016;98-B(1):58-64.

33. Kim KT, Lee S, Ko DO, Seo BS, Jung WS, Chang BK. Causes of failure after total knee arthroplasty in osteoarthritis patients 55 years of age or younger. Knee Surg Relat Res. 2014;26(1):13-9.

34. Sedel L, Simeon J, Meunier A, Villette JM, Launay SM. Prostaglandin E2 level in tissue surrounding aseptic failed total hips. Effects of materials. Arch Orthop Trauma Surg. 1992;111(5):255-8.

35. Boutin P. Total hip arthroplasty using a ceramic prosthesis. Pierre Boutin (1924-1989). Clin Orthop Relat Res. 2000;(379):3-11.

36. Bizot P, Hannouche D, Nizard R, Witvoet J, Sedel L. Hybrid alumina total hip arthroplasty using a press-fit metal-backed socket in patients younger than 55 years. A six- to 11-year evaluation. J Bone Joint Surg Br. 2004;86(2):190-4.

37. Hamadouche M, Boutin P, Daussange J, Bolander ME, Sedel L. Alumina-onalumina total hip arthroplasty: a minimum 18.5-year follow-up study. J Bone Joint Surg Am. 2002;84-A(1):69-77.

38. Ezzet KA, Hermida JC, Colwell CW Jr, D'Lima DD. Oxidized zirconium femoral components reduce polyethylene wear in a knee wear simulator. Clin Orthop Relat Res. 2004;428:120-4.

39. White SE, Whiteside LA, McCarthy DS, Anthony M, Poggie RA. Simulated knee wear with cobalt chromium and oxidized zirconium knee femoral components. Clin Orthop Relat Res. 1994;309:176-84.

40. Heyse TJ, Chen DX, Kelly N, Boettner F, Wright TM, Haas SB. Matched-pair total knee arthroplasty retrieval analysis: oxidized zirconium vs. CoCrMo. Knee. 2011;18(6):448-52

41. Hallab N, Merritt K, Jacobs JJ. Metal sensitivity in patients with orthopaedic implants. J Bone Joint Surg Am. 2001;83-A(3):428-36.

42. Hamilton WG, McAuley JP, Dennis DA, Murphy JA, Blumenfeld TJ, Politi J. THA with Delta ceramic on ceramic: results of a multicenter investigational device exemption trial. Clin Orthop Relat Res. 2010;468(2):358-66.

43. Hui C, Salmon L, Maeno S, Roe J, Walsh W, Pinczewski L. Five-year comparison of oxidized zirconium and cobalt-chromium femoral components in total knee arthroplasty: a randomized controlled trial. J Bone Joint Surg Am. 2011;93(7):624-30.

44. Kim YH, Park JW, Kim JS. Comparison of the Genesis II total knee replacement with oxidised zirconium and cobalt-chromium femoral components in the same patients: a prospective, double-blind, randomised controlled study. J Bone Joint Surg Br. 2012;94(9):1221-7.

Ready to submit your research? Choose BMC and benefit from:

- fast, convenient online submission

- thorough peer review by experienced researchers in your field

- rapid publication on acceptance

- support for research data, including large and complex data types

- gold Open Access which fosters wider collaboration and increased citations

- maximum visibility for your research: over $100 \mathrm{M}$ website views per year

At BMC, research is always in progress.

Learn more biomedcentral.com/submissions 